\title{
CORROSION BEHAVIOR OF A WC/C COATED 7075-T6 ALUMINUM ALLOY
}

\author{
S. Baragetti ${ }^{1,2, a}$, M.Daurù ${ }^{3, b}$, R.Gerosa ${ }^{4, c}$, B.Rivolta ${ }^{4, c}$ \\ ${ }^{1}$ Department of Engineering, University of Bergamo, Viale Marconi 5, Dalmine 24044, Italy \\ ${ }^{2}$ GITT - Centre on Innovation Management and Technology Transfer, University of Bergamo, Via \\ Salvecchio 19, Bergamo 24129, Italy \\ ${ }^{3}$ LAFER SpA, Strada di Cortemaggiore, 31 - Borghetto di Roncaglia, 29122 Piacenza, Italy \\ ${ }^{4}$ Politecnico di Milano, Polo territoriale di Lecco, Via Marco D'Oggiono 18/A, 23900 Lecco, Italy \\ asergio.baragetti@unibg.it, ${ }^{b}$ dauru@lafer.eu, ${ }^{c}$ riccardo.gerosa@polimi.it, ${ }^{d}$ barbara.rivolta@polimi.it
}

Keywords: 7075 aluminium alloy, WC/C coating, intergranular corrosion.

\begin{abstract}
In the present experimental work, a WC/C coated 7075-T6 aluminum alloy was considered from the corrosion point of view. The coating was deposited by PVD technique with a final thickness of about $2.5 \mu \mathrm{m}$. In order to study the influence of the coating on the corrosion behavior of the aluminum alloy, the samples surfaces were partially coated and the interface among the metal and the coating was analyzed after the corrosion tests described into the ASTM G110 standard. Such experimental plan was decided in order to simulate the possible in-service local removal of the thin and hard coating. This kind of damage, due for example to a foreign object impact, can occur because of the great hardness difference between the coating and the substrate. The experimental tests were carried out on samples with different surface finishing, ranging from about $0.02 \mu \mathrm{m} R a$ (mirror-polished surface) to about $0.8 \mu \mathrm{m} R a$ (320 grit paper). The aim of such choice was to investigate the effect of a surface roughness different from the optimal one (mirror polished) on the coating deposition. Moreover a different corrosion resistance is expected.
\end{abstract}

\section{Introduction}

7075 is an high performance aluminum alloy well known and appreciated in the automotive and aerospace fields. In the T6 temper, the mechanical properties are maximized even though the corrosion resistance is generally rather poor. Another critical aspect of the aluminum alloys is the wear resistance. In order to improve both the corrosion and the wear behavior, the deposition of thin hard coatings, generally by PVD technique [1-3], is carried out. Nevertheless the choice of the best solution is influenced by the deposition temperature of the most common coatings, generally higher than the aging temperature of the T6 temper, i.e. $121^{\circ} \mathrm{C}$. WC/C can be considered a good compromise to enhance the corrosion and wear resistances without a huge modification of the mechanical properties of the $\mathrm{T} 6$ temper. $\mathrm{WC} / \mathrm{C}$ coating deposition temperature is in fact equal to $180^{\circ} \mathrm{C}$. The superposition of such temperature on a $\mathrm{T} 6$ temper will be studied by means of hardness and intergranular corrosion tests. The presence of the coating is in fact positive for the corrosion resistance, but little information is available about the corrosion behavior in case of a possible inservice local removal of the coating. The corrosion resistance will be studied on samples with different surface finishing, ranging from about $0.02 \mu \mathrm{m} R a$ (mirror-polished surface) to about $0.8 \mu \mathrm{m}$ $R a$ (320 grit paper). The aim of such choice is to investigate the effect of a surface roughness different from the optimal one (mirror polished) on the coating deposition. Finally an estimation of the coating fracture toughness will be carried out, because poor information is available, as far as the authors know, in the technical literature. 


\section{Materials and Methods}

The considered aluminum alloy is a 7075- T6 whose chemical composition is reported in table 1.

Table 1. Chemical composition of the considered alloy.

\begin{tabular}{ccccccccc}
\hline Si [\%] & Fe [\%] & Cu [\%] & Mn [\%] & Mg [\%] & Zn [\%] & Cr [\%] & Ti [\%] & Al [\%] \\
\hline 0,22 & 0,30 & 1,65 & 0,10 & 2,45 & 5,70 & 0,21 & 0,11 & Bal. \\
\hline
\end{tabular}

The material was delivered as $\mathrm{T} 6$ thick plate $(90 \mathrm{~mm}$ thickness). The samples for the mechanical and corrosion tests were machined in the short-transverse direction of the plate, which is known to be the most critical direction. Tensile and hardness tests were performed to characterize the as delivered condition, whereas the effect of the temperature deposition process was investigated by means of hardness tests only. The intergranular corrosion resistance was investigated according to ASTM G110 on samples with different surface roughness ranging from about $0.02 \mu \mathrm{m} R_{a}$ (mirrorpolished surface) to about $0.8 \mu \mathrm{m} R_{a}(320$ grit paper) as reported in table 2 . The specimens were tested both before and after the coating (figure 1).

Table 2. Average surface roughness of the uncoated (A, B and C) and the coated samples (E, F and G) before and after the deposition. The roughness was measured by a Taylor Hobson profilometer.

\begin{tabular}{ccc|ccc}
\hline Surface finishing & Sample id. & $\mathbf{R}_{\mathbf{a}}[\boldsymbol{\mu m}]$ & Sample id. & $\begin{array}{c}\mathbf{R}_{\mathbf{a}}[\boldsymbol{\mu m}] \\
\text { before coating }\end{array}$ & $\begin{array}{c}\mathbf{R}_{\mathbf{a}}[\boldsymbol{\mu m}] \\
\text { after coating }\end{array}$ \\
\hline Mirror-finished & A & 0.04 & E & 0.04 & 0.03 \\
1200 grit paper & B & 0.29 & F & 0.29 & 0.31 \\
320 grit paper & C & 0.79 & G & 0.79 & 0.81 \\
\hline
\end{tabular}

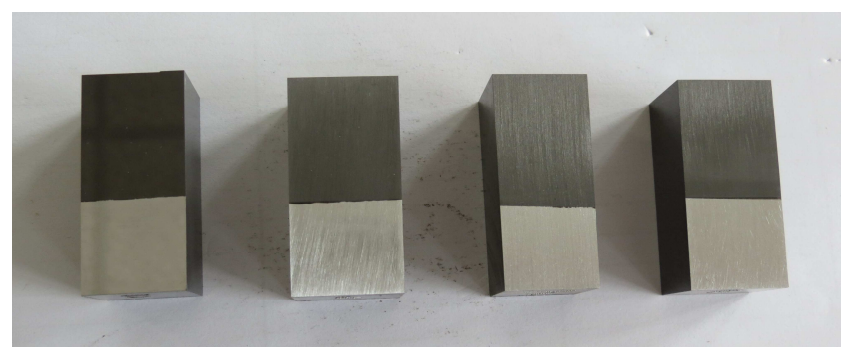

Figure 1. Samples after the $\mathrm{WC} / \mathrm{C}$ deposition.

In order to study the effects of the corrosive environment, a suitable procedure was used to quantify the shape and the distribution of the defects as described in [4]. According to such method, the corrosive attack can be evaluated by the following parameter:

$R_{c}=R^{*} \cdot C_{s}$

where $R^{*}$ is the average of the $R_{i}{ }^{*}$ values defined in equation 2 and $\mathrm{C}_{\mathrm{s}}$ is the corroded profile length.

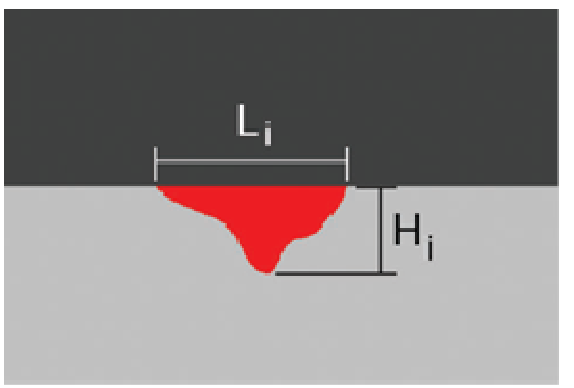

Figure 2. Image analysis of a defect.

$$
R_{i}^{*}=R_{i} \frac{H_{i}}{L_{i}}
$$

where $R i=P_{i}^{2} / 4 \pi S_{i}-P_{i}$ and $S_{i}$ are the perimeter and the area of the defect (identified by the red region in figure 2) respectively. Being the accidental removal of the coating one of the considered 
issues, the estimation of the coating fracture toughness was carried out by Vickers indentation tests and through a different approach based on the round plane sheets theory [5]. This method is considered preliminary for a future FEM analysis.

\section{Results}

From static point of view, the coating thermal cycle caused a decrease of the mechanical resistance as shown in table 3.

Table 3. Average mechanical properties before and after the coating process.

\begin{tabular}{ccc|c}
\hline \multicolumn{3}{c|}{ As delivered } & After coating deposition \\
\hline $\mathbf{R}_{\mathbf{p 0 2}}[\mathbf{M P a}]$ & UTS [MPa] & HV10 & HV10 \\
\hline 485 & 559 & 172 & 151 \\
\hline
\end{tabular}

The corrosion behavior of the alloy in the T6 temper was rather bad for all the considered surface finishes (figure 3): the image analysis revealed that the surface roughness mainly influences the amount and the distribution of the pits rather than their shape. The corrosion indexes are reported in table 4 .

Table 4. Results of the image analysis on the corroded 7075 T6 samples.

\begin{tabular}{cccc}
\hline $\begin{array}{c}\text { Corrosion } \\
\text { parameter }\end{array}$ & Mirror polished & $\mathbf{1 2 0 0}$ grit paper & 320 grit paper \\
\hline $\mathrm{R}^{*}$ & 15.9 & 20.2 & 22.2 \\
$\mathrm{C}_{\mathrm{s}}[\%]$ & 40.3 & 55.9 & 60.3 \\
$\mathrm{R}_{\mathrm{c}}$ & 6.4 & 11.3 & 13.4 \\
\hline
\end{tabular}
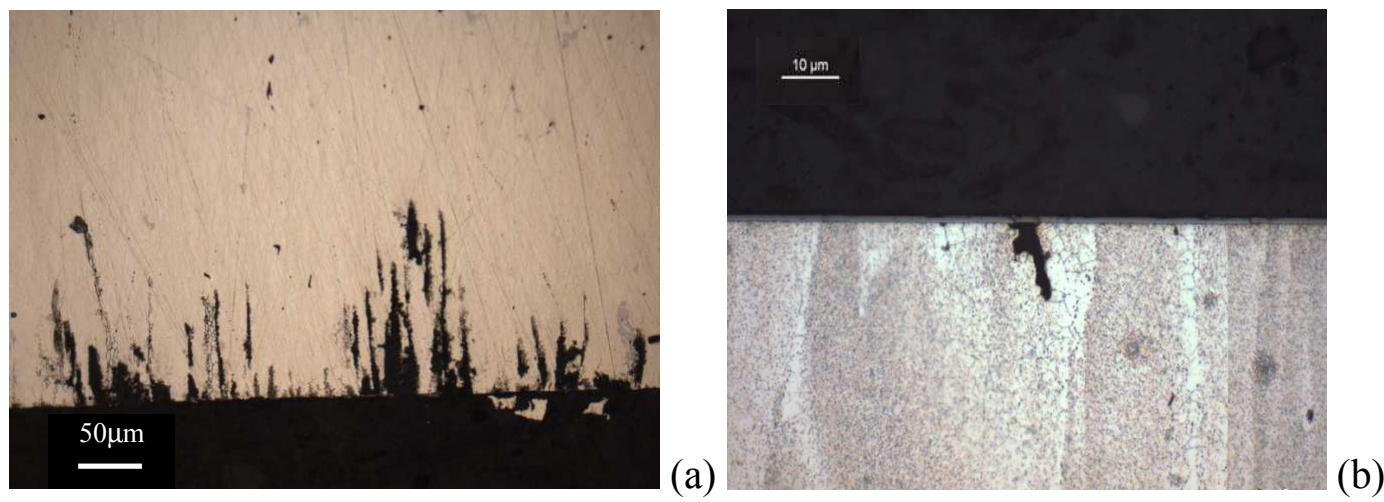

Figure 3. Corrosion pits for 320 grit paper polished (a) and coated (b) samples.

The observation of the coated specimens showed that where the coating is not present because of a possible damage or small deposition defect, the corrosion attack may occur and the coating can be further removed. For such a reason the coating fracture toughness was estimated. The first method was based on Vickers indentation tests that resulted in circumferential cracks of the coating.

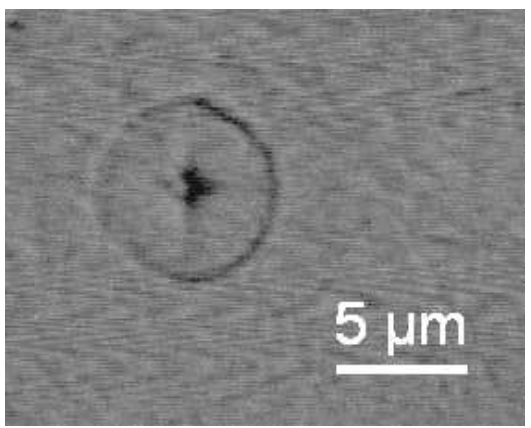

Figure 4. Circumferential crack $(\mathrm{d} \approx 8.2 \mu \mathrm{m})$ observed after the application of the critical load $0,0981 \mathrm{~N}$. No cracks were found for lower loads 
According to [6], the coating fracture toughness can be expressed as:

$$
K=\sqrt{\frac{U}{2 \pi r h} \cdot E^{*}}
$$

where $U$ is the energy related to coating fracture, calculated as difference among the indentation curves of coated and uncoated samples, $r$ is the circumferential crack radius, $h$ is the coating thickness (about $1.2 \mu \mathrm{m}$ ) and $E^{*}$ is the Young modulus of the coating-substrate system (measured by means of indentation tests and equal to about $115 \mathrm{GPa})$. A second approach based on the round plane sheets theory was used considering the indentation load concentrated in the middle of the circumferential crack and the substrate as a support below the coating. Finally the fracture toughness was estimated.

$$
K=1.12 \sigma \sqrt{\pi s}=0.107 \frac{F}{s^{2}} \sqrt{\pi h}
$$

where $F$ is the critical indentation load $(0.0981 \mathrm{~N})$ and $s$ is the effective coating-substrate system thickness related to the maximum indentation depth. A comparison between the two methods is reported in table 5 .

Table 5. Comparison among the fracture toughness results.

\begin{tabular}{lcc}
\hline & Indentation tests & Plane sheets theory \\
\hline K $\left[\mathrm{MPam}^{0.5}\right]$ & 6.64 & 7.11 \\
\hline
\end{tabular}

\section{Conclusions}

The present investigation led to the following conclusions:

- the coating process causes a decrease of the mechanical properties being the deposition temperature higher than the T6 temper aging one;

- the corrosion behavior of the as delivered alloy is influenced by the surface roughness in terms of pits distribution. The shape of the defects, instead, mainly depends on the grain size;

- some corrosion pits were observed on the coated specimens. Their nucleation can start from a small defect due to an accidental removal or to a deposition defect, but when the corrosion attack occurs, the coating can be further removed or strongly damaged;

- the coating fracture toughness was estimated by using different approaches resulting in very similar values. Nevertheless further investigations and analysis are necessary because of the poor information available in the technical literature.

\section{References}

[1] Wheeler DW. In: Mellor BG (Ed.). Surface coatings for protection against wear, Abington, UK: Woodhead Publishing Ltd.; 2006, p. 101.

[2] Bull SJ. In: Mellor BG (Ed.). Surface coatings for protection against wear, Abington, UK: Woodhead Publishing Ltd.; 2006, p. 146.

[3] Bayón R, Igartua A, Fernández X, Martínez R, Rodríguez RJ, García JA et al. Corrosion-wear behaviour of PVD Cr/CrN multilayer coatings for gear applications. Tribol Int 2009; 42:591-9.

[4] Silva G., Rivolta B., Gerosa R., Derudi U., 'Quench sensitivity' of 7075 aluminium alloy plates, International Heat Treatment and Surface Engineering 2009 VOL $3 \mathrm{~N}^{\circ} 4$.

[5] Bazzaro E., Gorla C., Miccoli S., Lezioni di Tecnica delle Costruzioni Meccaniche, Edizioni Spiegel, 1997.

[6] Bahr D.F., Morasch K.R., Alamr A., Indentation induced through thickness film fracture on engineering alloys, 16th European Conference of Fracture (ECF16), Alexandroupolis, Greece. 
Advances in Fracture and Damage Mechanics XII

10.4028/www.scientific.net/KEM.577-578

Corrosion Behavior of a WC/C Coated 7075-T6 Aluminum Alloy

10.4028/www.scientific.net/KEM.577-578.217 